\title{
Evde bakım hizmetinden yararlanan hastaların sosyodemografik özellikleri ve tıbbi durumlarının değerlendirilmesi
}

\section{Evaluating sociodemographic and medical conditions of patients under home care service}

\author{
Tolga Önder ${ }^{1}$, Turgut Anuk² ${ }^{2}$ Şahin Kahramanca ${ }^{3}$, Ali Cihat Yıldırım ${ }^{3}$
}

\section{ÖZET}

Amaç: Çalışmada evde bakım hizmetleri kapsamındaki hastaların sosyodemografik özellikleri ve tıbbi durumlarını ortaya koymak amaçlandı.

Yöntemler: Çalışma Haziran 2013 - Mayıs 2014 tarihleri arasında Sarıkamış Devlet Hastanesi bünyesinde evde bakım hizmetlerine kayıtlı 52 hasta üzerinde planlandı. Hastaların cinsiyet, eğitim durumları, sosyal güvenlik durumları, komorbid hastalıkları ve genel sağlık durumları kaydedildi.

Bulgular: Çalışmaya evde bakım hizmetlerine kayıtlı 21'i erkek $(\% 40,4)$, 31'i kadın $(\% 59,6)$ toplam 52 hasta dahil edildi. Hastaların 36'sının $(\% 69,2)$ hiçbir okul eğitimi almadıkları, 16'sının $(\% 30,8)$ ise sadece ilkokul eğitimi aldığı saptandı. Bayan hastaların tamamı ev hanımı idi. Evde bakım hizmetinden faydalanan hastalarda en sık saptanan hastalıklar sırası ile $18(\% 34,6)$ serebrovasküler hastalık (SVH), 9 (\%17,3) Alzheimer ve $4(\% 7,7)$ kronik obstruktif akciğer hastalığı (KOAH) idi. Hastaların $\% 73,1^{\prime}$ i (38 hasta) rutin takip intiyacı duyarken 14 hastanın $(\% 26,9)$ rutin takip intiyacı yok idi. Hastaların sosyal güvenlik durumları incelendiğinde $\% 61,5$ hastanın yeşil kart sahibi olduğu gözlendi. Sadece 6 hastanın $(\% 11,5)$ narkotik analjezik ihtiyacı vardı. On üç hastada immobilizasyona bağlı bası ülseri mevcut idi. Hastaların efor kapasiteleri değerlendirildiğinde; 43 hastanın kendi kendine giyinemediği, 38 hastanın telefon dahi kullanamadığı saptandı. Otuz iki hastada idrar inkontinansı, 31 hastada gaita inkontinansı mevcut idi.

Sonuç: Günümüzde evde bakım hizmetlerine ihtiyaç duyan hasta popülasyonu, daha fazla hastanın evde bakım hizmetlerine ulaşım imkanı bulması ve yaşam süresinin uzamasına bağlı olarak giderek artmaktadır. Evde Bakım Hizmetine ihtiyaç duyan hastaların daha iyi ve doğru hizmet alabilmeleri için Evde Bakım Hizmeti veren personelin eğitimi iyi planlanmalı ve hastaların özellikleri ve tıbbi durumlarının bölgesel farklılıklar gösterebileceği dikkate alınmalıdır.

Anahtar kelimeler: Evde bakım hizmeti, geriatrik, sağlık politikası

\author{
ABSTRACT \\ Objective: In our study, we aimed to reveal medical con- \\ ditions and the sociodemographic conditions of patients \\ under home care service.
}

Methods: Our study is planned on 52 patients who are under home care service at Sarıkamış State Hospital between June 2013 and May 2014. Patients' sex, education, social security status, comorbid diseases and general health status were recorded.

Results: Fifty-two patients enrolled. 21 of them (40.4\%) were men, 31 of them (59.6\%) were women. It is revealed that In 36 patients $(69.2 \%)$ did not receive formal education throughout their lives, while16 (30.8\%) of them had only primary education. All female patients were housewives. The most frequent diseases in home care patients were cerebrovascular disease in 18 (34.6\%) subjects, Alzheimer's disease in $9(17.3 \%)$, and chronic obstructive pulmonary disease in $4(7.7 \%) \mathrm{d}$. 38 patients $(73.1 \%)$ needed routine follow-up. Most of the patients $(61.5 \%)$ had green card health insurance. Only 6 patients $(11.5 \%)$ were in need of narcotic analgesics. Thirteen patients had pressure ulcers due to immobilization. Evaluating the exercise capacity of the patients; 43 (82.7\%) could not dressed themselves, $38(73.1 \%)$ could not use phone. Thirty-two patients had urinary incontinence and 31 had fecal incontinence.

Conclusion: Today, population of patients who need home care service is increasing due to ease access to home care service and increase in survival. For a better care of patients, home care providers should be well educated and differences on features of patients and medical conditions it should be taken into consideration.

Key words: Under home care, geriatric, health policy

${ }^{1}$ Sarıkamış Devlet Hastanesi Genel Cerrahi, Kars, Türkiye

${ }^{2}$ Kars Kafkas Üniversitesi Tip Fakültesi Genel Cerrahi AD, Kars, Türkiye

${ }^{3}$ Kars Devlet Hastanesi Genel Cerrahi, Kars, Türkiye

Yazışma Adresi /Correspondence: Tolga Önder,

Sarıkamış Devlet Hastanesi Genel Cerrahi, Kars, Türkiye Email: tlgonder@gmail.com

Geliş Tarihi / Received: 29.05.2015, Kabul Tarihi / Accepted: 04.08.2015

Copyright (C) Dicle Tıp Dergisi 2015, Her hakkı saklıdır / All rights reserved 


\section{GíRiş}

Evde bakım hizmeti (EBH), temel sağlık hizmetlerinde devamlılığg sağlayan önemli bir modeldir [1]. Evde bakım hizmetleri, yaşl1, fiziksel ve zihinsel özürlü, kronik hastalığı olan veya iyileşme sürecindeki bireyleri kendi ortaminda destekleyen, sosyal yaşama ayak uydurmalarını sağlayıp yaşamlarını mutlu ve huzurlu bir biçimde sürdürerek, bakıma ihtiyaç duyan bireyin, aile üyeleri üzerindeki yükünü hafifletmek için birey ve aileye sunulan psikososyal, fizyolojik ve tıbbi destek hizmetleri ile sosyal hizmetleri içermektedir [2]. Evde bakım desteği sayesinde insanlar, gerekli duydukları periyodik bakımlarını yaptırmak ve tedaviyi üstlenecek kişiyi seçme hakkına da sahip olmaktadırlar [3].

Evde bakım hizmetlerinin tarihi incelendiğinde, program ilk olarak $1947^{\prime}$ de tıbbi, hemşirelik ve sosyal hizmetlerin sunulmasi amaci ile hastane destekli olarak başlatılmıştır [4]. Ülkemizde ise 10 Mart 2005 tarihinde 25751 sayılı Resmi Gazete'de yayınlanan "Evde Bakım Hizmetleri'nin Sunumu Yönetmeliği'ne" göre oluşturulmuştur. Bu yönetmelikte $\mathrm{EBH}$, hekim önerileri doğrultusunda hasta kişilere, aileleri ile yaşadıkları ortamda, sağlık ekibi tarafindan rehabilitasyon, fizyoterapi, psikolojik tedavide dahil tıbbi gereksinimlerini karşılayacak şekilde sağlık bakımı ile sağlık hizmetlerinin sunulması şeklinde tanımlanmıştır [5].

Evde bakım hizmeti alan hastaların büyük çoğunluğu 50 yaş ve üzerindedir. Yaşlılık ile birlikte kronik hastalık ve bağımlılık oranları artar ve bununla doğru orantılı olarak evde bakım hizmetlerine gereksinim artar. Yaşlı populasyondaki hastaların gereksinimleri diğer yaş grubundaki hastalara göre farklıl1k göstermektedir [6-8]. Kronik hastalıklar, geriatrik toplumlarda hızla artış göstermektedir. $\mathrm{EBH}$, bu populasyondaki hastalarda tam olarak iyileşme sağlayamasa da, hastaların yaşam sürelerinde artışa neden olmaktadır.

Günümüzde yaşamın uzunluğundan ziyade, yaşam kalitesi daha önemlidir. Yaşam kalitesi bireyin iyilik halinin bir göstergesidir [9]. Ülkemizde bu alanda yapılacak olan çalışmalar yaşam kalitesinin arttırılması açısından büyük önem taşımaktadır. Çalışmamızda, evde bakım hizmetlerine ihtiyaç duyan hastaların sosyodemografik özeliklerini belirleyerek, evde bakım hizmetlerinde görevli perso- nele tedavinin yürütülmesi konusunda 1 şı tutmak amaçland1.

\section{YÖNTEMLER}

Bölgemizde Evde Bakım Hizmeti iki hemşire, bir genel cerrahi uzmanı ve bir ambulans şoförü tarafindan yürütülmektedir. Çalışma, Haziran 2013 - Mayıs 2014 tarihleri arasında Sarıkamış Devlet Hastanesi Evde Bakım Hizmetleri Biriminde tanımlayıcı nitelikte bir çalışma olarak planlandı. Belirtilen tarihler arasında evde bakım hizmeti alan 52 hasta çalışmaya dahil edildi. Hastalara ait sosyodemografik özellikler ve tıbbi durumlarına ait veriler, araștırmacılar tarafından olușturulmuș anket formu ile toplandı. Anketler hasta ve yakınlarının sözel onamları alınarak, Evde Bakım Hizmeti biriminde görevli hekim ve hemşireler tarafından, hasta evlerine tek tek gidilerek dolduruldu ve çalışma hakkında bilgilendirme yapıldı. İstatistiksel analiz. Verilerin analizi, SPSS Windows 20 (Chicago, İL, USA) paket programında yapıldı. Kategorik değişkenler olgu sayısı ve (\%) oran şeklinde gösterildi.

\section{BULGULAR}

Belirtilen tarihler arasında evde bakım hizmetlerinden faydalanan hasta sayıs1 52 olarak tespit edildi. Hastaların \%94,2' sinin (49 hasta) 50 yaş ve üzerinde olduğu tespit edildi. Hastaların 21 'i $(\% 40,4)$ erkek, 31 tanesi $(\% 59,6)$ kadın idi. Eğitim durumlarına bakıldığında 36 hastanın $(\% 69,2)$, hiçbir okul eğitimi almadı $\breve{g}$, geriye kalan 16 hastanın ise $(\% 30,8)$ sadece ilkokul eğitimi aldığ saptandı. Hastalar meslek grupları açısından değerlendirildiğinde, hastaların büyük çoğunluğunu ev hanımlarının oluşturduğu saptandı (31 hasta).

Hastalar, komorbid hastalıklarına göre incelendiğinde; 18 hasta $(\% 34,6)$ ile serebrovasküler hastalıklar en büyük grubu oluşturmakta idi. Bunu 9 hasta $(\% 17,3)$ ile Alzheimer hastalığı takip etmekte idi. Hastaların hepsinin ayda en az bir kez takibi yapılmakta idi. Otuz iki hastanın sosyal güvencesi $(\% 61,5)$ yeşil kart idi. Hastaların 6'sında $(\% 11,5)$ narkotik analjezik ihtiyacı olduğu tespit edildi. $\mathrm{Bu}$ hastaların 1'i malignite, diğerleri ise kas iskelet sistemi rahatsızlığ 1 nedeni ile narkotik analjezik kullanmakta idi. On üç hastada (\%25) bası ülseri saptandı. Sadece 1 hastanın $(\% 1,9)$ sürekli solunum 
desteği ihtiyacı vardı. Hastaların \%80,8'i yardımsız yemek yiyebilmekte idi. Yirmi beş hasta $(\% 48,1)$ yardımsız hareket edebilirken, 27 hasta $(\% 51,9)$ hareket etmek için başka bir kişiye bağımlı idi. Hastalar yaşam aktiviteleri yönünden sorgulandıklarında, 47 hastanın $(\% 90,4)$ yardımsız banyo yapamadığ 43 hastanın $(\% 82,7)$ yardımsız giyinemediği tespit edildi. Hastaların 14'ü $(\% 26,9)$ telefon kullanabilmekte, sadece 3'ü $(\% 5,8)$ kendi kendine alışveriş yapabilmekte idi. Hastaların büyük çoğunluğunun $(n=50)$ ev işlerini kendi kendine yapamadığı saptandi.

Hastaların kendi ilaçlarını yardımsız alıp alamadıkları sorgulandığında; 18 hastanın $(\% 34,6)$ yardımsız ilaçlarını alabildiği tespit edildi. Otuz iki hastada $(\% 61,5)$ idrar inkontinans1, 31 hastada ise gaita inkontinansı saptand1. Hastaların primer sorumluluğunu alan kişiler sorgulandığında, en büyük grubu, hastaların gelinleri oluşturmakta idi (n:34). Hastalardan evde sorumlu olan kişilerin hemen hemen tamamının (\%98) kadın olduğu saptandı.

Hastaların evde bakım hizmetlerinden ne şekilde haberdar oldukları sorgulandığında, hastaların \%53,8'i (28 hasta) doktorlarının kendilerini yönlendirdiğini, 24 hasta $(\% 46,2)$ ise çevrelerinden duyduklarını belirtti. Hastalardan 24 'ünün $(\% 46,2)$ takipleri dahiliye kliniğinde, 13 ‘ünün $(\% 25)$ ise nöroloji kliniğinde yapılmakta idi.

\section{TARTIŞMA}

Evde bakım hizmetinden yararlanan 52 hasta değerlendirildiğinde hastaların \%94,2'sinin (49 hasta) yapılan çalışmalarla benzer özellikte olarak 50 yaş ve üzerinde olduğu tespit edildi. Yaş ilerledikçe hastaların hastalıklarına bağlı olarak kalıcı motor defisitlere sahip olmaları ve buna bağlı olarak fonksiyonlarında kisitlılık olması beklenen bir bulgudur [10]. Yapılan bir çalışmada yaşlıların \%6,5' inin yardımsız banyo yapamadığ $1, \% 2,8$ 'inin tek başına giyinip soyunamadığ $1, \% 1,4$ 'ünün tuvalet ihtiyacını karş1layamadı̆̆ 1 , \%1,7'sinin oturamadığ 1 , \%0,3'ünün tek başına yemek yiyemediği, \%1,1'inin telefon kul-lanamadığ $1, \% 35,9$ 'unun alışveriş yapamadığı, \%44'ünün yemeğini hazırlayamadığı, \%20,3'ünün ev işlerine katılamadığı, \%25,4'ünün çamaşırlarını yıkayamadığı, \%25,4'ünün ilaçlarını doğru dozda ve zamanında alamadığ 1 ve \%12,4'ünün para hesab1 yapamadığı belirtilmiştir [11].
Bizim çalışmamızdaki hastaların yardım gereksinimlerinin yapılan çalışmaya göre daha fazla olduğu saptandı. Bölgemizde evde bakım hizmetler-ine ihtiyaç duyan hastaların evde bakım hizmetinden yararlanmak için başvuruların oldukça geç yapıldığ 1 tespit edilmiştir. Bağımlı hasta sayısının benzer çalışmalara oranla daha fazla bulunması, evde bakım hizmetine başvuruların geç yapılması ile bağlantılı olabilir. Ayrıca bu kadar bağımlı yaşayan bir hasta grubunda sadece evde bakım hizmetlerinden yardım beklemek yerine aile içerisinden de primer sorumlu kişilerin bulunması gerekliliği ortaya konmuştur. Çalışmamızda da yapılan çalışmalara [12] benzer özellikte, hastaların \%96.1'inin ev içerisinde primer ilgilenen bir akrabası bulunmakta idi. Hastalardan ev içerisinde primer sorumlu olan kişilerin çoğunlukla $(n=34)$ evin gelinleri olduğu saptandi.

$\mathrm{Bu}$ bize hasta sayıs1 sinırlı olmakla birlikte özellikle Doğu Anadolu Bölgesindeki erken yaştaki evlilikleri açıklamak konusunda bir fikir verebilir. Narkotik analjezik ihtiyacı olan hastaların \%83,4'ünün (5 hasta) kas iskelet sistemi rahatsızlıkları nedeni ile bu ihtiyaçlarının doğduğu tespit edildi. Yapılan benzer çalışmalarda da kas iskelet sistemi rahatsızlıklarının hasta konforunu etkileyen en önemli problem olduğu bildirilmiştir [12]. Yapılan diğer çalışmalara benzer olarak çalışmamızda da üriner ve fekal inkontinans izlenmiştir $[13,14]$. Literatürdeki çalışmalara benzer şekilde, çalışmamızdaki hastalarda bası ülseri $\% 25$ oranında tespit edilmiştir ve hala çözülmesi gereken oldukça önemli bir problem olduğu tespit edilmiştir $[10,15]$. Hastaların sağlık güvenceleri bölge nüfusu ile doğru orantılıydı ve yeşil kart sahibi hasta say1s1 fazla idi. Hastaların primer takiplerinin yapıldığ 1 klinikler, çoğunlukla dahiliye ve nöroloji klinikleri olarak saptanmıştır. Her iki kliniğinde takip ettiği hasta popülasyonuna bakıldığında çoğunlukla kronik hastalıkların takip edildiği görülmekte ve bizim bulgularımız ile örtüşmektedir.

Evde bakım hizmetinden yararlanması gereken hasta sayısı özellikle yaşam süresinin uzamas1 ile birlikte giderek artmaktadır. Bu nedenledir ki evde bakım hizmetlerinde görev yapan personelin de daha iyi hizmet verebilmesi açısından hangi sorunlarla karşılaşacağı konusunda yeterli bilgi ve donanıma sahip olması gerekir. Biz bu çalışmada özellikle EBH veren personele 1şı tutması açısın- 
dan Kuzey Doğu Anadolu bölgesinde evde bakım hizmeti alan hastaların sosyodemografik özellikleri ve tıbbi durumlarını ortaya koymaya çalıştık. Hasta özellikleri ve tıbbi durumlarının bölgesel farklılıklar gösterebileceği unutulmamalı ve EBH alan hastalara daha iyi hizmet sunulması açısından bölgesel yeni çalışmalar yapılmalıdır.

Teşekkür: Hasta verilerinin toplanmasındaki katkılarından dolayı Özge Önder'e teşekkür ederiz.

\section{KAYNAKLAR}

1. Coşkun, M. (1998). Samsun İl Merkezinde Yaşayan Yaşl1ların Sürekli Kaygı Düzeyleri ve Bazı Sosyoekonomik Etmenleri, Ondokuz Mayıs Üniversitesi Tıp Fakültesi, Halk Sağlığı Anabilim Dalı Uzmanlık Tezi, Samsun.

2. Danış MZ. Toplum Temelli Bakım Anlayışı. Özveri Dergisi 2006:3:44-47.

3. Aksayan S. ve Cimete G. (1998). Kronik Hastalıklı Bireylerin Evde Bakım Gereksinimleri Olanakları ve Tercihleri. I.Ulusal Evde Bakım Kongresi Kitabı,24-26 Eylül 1998. İstanbul 95-100.

4. Fadıloğlu, Ç. Yaşlılıkta Psikososyal Sorunlar. Ege Üniversitesi. Hemşirelik Yüksekokulu Dergisi 1992;42:63-73.

5. Başbakanlık Mevzuatı Geliştirme ve Yayın Genel Müdürlügü. Evde Bakım Hizmetleri Sunumu Hakkında Yönetmelik. Ankara, 10.03.2005; Resmi Gazete: Say1 25751.

6. Kane RL. Geriatrics as a paradigm for chronic care. Age and Ageing 2002;31:331-332.
7. Kutsal YG. Yaşlanan dünya, yaşlanan toplum, yaşlanan insan. Hacettepe Toplum Hek Bült 2003;24:1-6.

8. Sahyoung NR, Lentzner H, Hovert D, Robinson KN. Trends in causes of death among the elderly. Centers for Disease Control and Prevention. National Center for Health for Statistics, 2001.

9. Ertem G, Kaklım A, Bulut S, Sevil Ü. Radyoterapi alan hastaların evde bakım gereksinimleri ve yaşam kaliteleri.

10. Akdemir N, Bostanoğlu H, Yurtsever S, et al. Yatağa ba$\breve{g}$ ımlı hastaların evde yaşadıkları sağlık sorunlarına yönelik evde bakım hizmet gereksinimleri. Dicle Tip Dergisi 2011;38:57-65.

11. Çölgeçen E, Tümerdem Y. Yaşlıların evde bakım hizmetlerine olan gereksinimleri. I. Ulusal Evde Bakım Kongre Kitab1 1998;175-186.

12. Enginyurt Ö, Öngel K. Sociodemographic characteristics and medical conditions of patients under homecare service Symrna Tip Dergisi 2012;45-48.

13. Long A, Heskheg A, Bowen A, et al. Communication outcome after stroke: a new measure of the carer perspective". Clin Rehabil 2009;23:846-856.

14. Haley WE, Allen JY, Grant JS, et al. Problems and benefits reported by stroke family caregivers: results from a prospective epidemiological study. Stroke 2009;40:2129-2133.

15. Sackley C, Brittle N, Patel S, et al. The prevalance of joint contractures, pressure sores, painful shoulder, other pain, falls and depression in the year after a severely disabling stroke. Stroke 2008;39:3329-3334. 